\title{
THREE ULTRASTRUCTURAL MARKERS ON PACHYTENE BIVALENTS OF HUMAN SPERMATOCYTES
}

\author{
by \\ JØRGEN G. BERTHELSEN, PREBEN B. HOLM and SØREN W. RASMUSSEN \\ Laboratory of Reproductive Biology, University Department of \\ Obstetrics and Gynaecology YA, Rigshospitalet, Copenhagen \\ Carlsberg Laboratory, Department of Physiology, \\ Gamle Carlsberg Vej 10, DK-2500 Copenhagen, Valby
}

Keywords: Synaptonemal complex, chromosome classification

\begin{abstract}
The occurrence and morphology of three ultrastructural markers on meiotic chromosomes are described on the basis of three dimensional reconstructions of 29 early pachytene and 28 mid-late pachytene nuclei: 1) A condensed granular structure surrounded by a larger body of uncondensed chromatin is situated near the telomere of the short arm of bivalent 1.2) A globoid structure with a fine granular substructure is present in the middle of the short arm of bivalent 6. 3) A body of coarse granules is situated near the middle of the long arm of one of the two longest $\mathrm{D}$ group bivalents.
\end{abstract}

\section{INTRODUCTION}

Previous investigations have shown that three dimensional reconstructions of synaptonemal complexes from human spermatocytes usually permit the identification of 14 of the 22 autosomal bivalents. This is done on the basis of their length and centromere index in combination with morphological markers on bivalents 1 , $9,13-15,16,21$ and $22(2,8)$.

The present report describes the occurrence and morphology of three new morphological markers on bivalents 1, 6 and possibly on 13. A preliminary description of the marker on biva- lent 6 is given by Berthelsen, Føgh and SKAKKEBÆK (1).

\section{MATERIALS AND METHODS}

The material consisting of complete reconstructions of 29 early and 28 mid-late pachytene nuclei from 7 men has previously been described by Holm and Rasmussen $(2,3)$, Rasmussen and Holm (8) and Berthelsen, Føgh and SkakkeB£K (1). In the present investigation, the 57 nuclei were reexamined for the presence of the ultrastructural markers. 

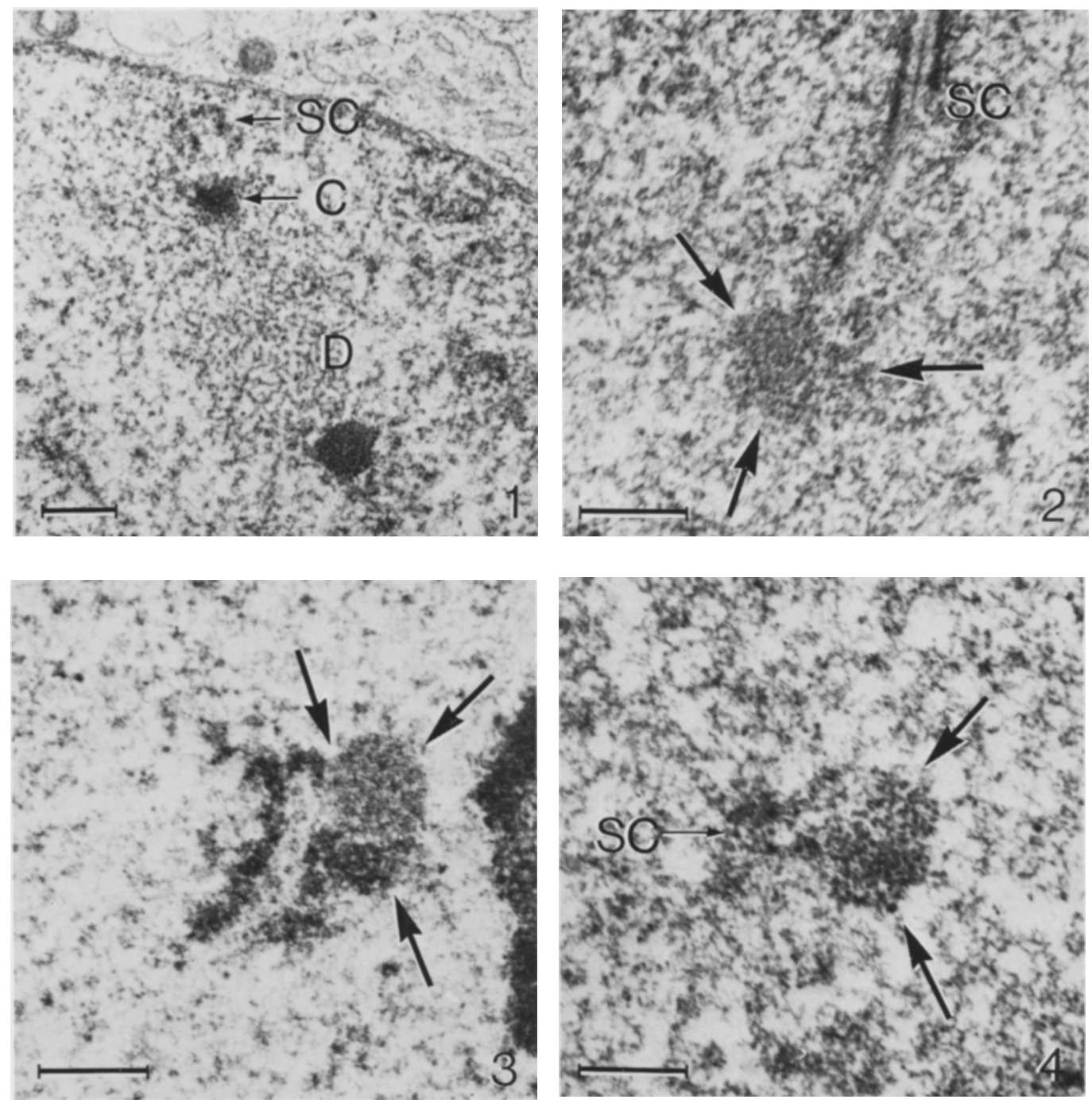

Figure 1. Marker number 1 from a late pachytene spermatocyte nucleus.

The marker consists of a condensed granular part (C) surrounded by a more diffuse part (D). SC, synaptonemal complex of bivalent 1 . (Bar $=0.5 \mu \mathrm{m})$.

Figure 2. Marker number 6 from an early pachytene spermatocyte nucleus.

The marker is spherical and composed of fine granules. SC, synaptonemal complex of bivalent 6 . (Bar = $0.5 \mu \mathrm{m})$.

Figure 3. Marker number 6 from a late pachytene nucleus. (Bar $=0.5 \mu \mathrm{m}$ )

Figure 4. Marker $D$ from an early pachytene spermatocyte nucleus.

The marker consists of coarse granules. SC, synaptonemal complex. (Bar $=0.5 \mu \mathrm{m})$.

\section{RESULTS AND DISCUSSION}

\subsection{Marker number 1}

Marker number 1 (Figure 1) which consists of a condensed granular part surrounded by a less compact part is located on the short arm of bivalent 1 at a mean distance of $0.7 \mu \mathrm{m}$ from the telomere. The mean diameter of the condensed granular part amounts to $0.27 \mu \mathrm{m}$ at early 
Table I.

The presence of chromosomal markers in 29 early pachytene nuclei of human spermatocytes. (The frequency is given as percent).

\begin{tabular}{cccccc}
\hline $\begin{array}{c}\text { Case } \\
\text { number }\end{array}$ & Reference & $\begin{array}{c}\text { Number } \\
\text { of } \\
\text { nuclei }\end{array}$ & $\begin{array}{c}\text { Frequency } \\
\text { of } \\
\text { marker } 1\end{array}$ & $\begin{array}{c}\text { Frequency } \\
\text { of } \\
\text { marker } 6\end{array}$ & $\begin{array}{c}\text { Frequency } \\
\text { of } \\
\text { marker D }\end{array}$ \\
\hline 1 & $(2)$ & 0 & - & - & - \\
2 & $(2)$ & 1 & 0 & 100 & 100 \\
3 & $(8)$ & 8 & 50 & 100 & 13 \\
4 & $(8)$ & 2 & 0 & 50 & 0 \\
5 & $(8)$ & 4 & 50 & 75 & 100 \\
6 & $(3)$ & 7 & 0 & 100 & 86 \\
7 & $(1)$ & 7 & 100 & 100 & 14 \\
\hline
\end{tabular}

Table II.

The presence of chromosomal markers in 28 mid-late pachytene nuclei of human spermatocytes. (The frequency is given as percent).

\begin{tabular}{cccccc}
\hline $\begin{array}{c}\text { Case } \\
\text { number }\end{array}$ & Reference & $\begin{array}{c}\text { Number } \\
\text { of } \\
\text { nuclei }\end{array}$ & $\begin{array}{c}\text { Frequency } \\
\text { of } \\
\text { marker } 1\end{array}$ & $\begin{array}{c}\text { Frequency } \\
\text { of } \\
\text { marker } 6\end{array}$ & $\begin{array}{c}\text { Frequency } \\
\text { of } \\
\text { marker D }\end{array}$ \\
\hline 1 & $(2)$ & 6 & 100 & 50 & 0 \\
2 & $(2)$ & 5 & 100 & 100 & 0 \\
3 & $(2)$ & 3 & 100 & 100 & 0 \\
4 & $(2)$ & 4 & 100 & 75 & 0 \\
5 & $(2)$ & 3 & 100 & 33 & 0 \\
6 & $(3)$ & 4 & 100 & 75 & 0 \\
7 & $(1)$ & 3 & 100 & 100 & 0 \\
\hline
\end{tabular}

pachytene and to $0.36 \mu \mathrm{m}$ at mid-late pachytene while the mean diameter of the uncondensed part is $1.50 \mu \mathrm{m}$ at early and $1.73 \mu \mathrm{m}$ at mid-late pachytene. The occurrence of the marker in nuclei from the 7 individuals analysed is given in Tables I and II. At mid-late pachytene, the structure can be recognized consistently while its presence at early pachytene is erratic.

\subsection{Marker number 6}

Marker number 6 is located near the middle of the short arm of the longest $\mathrm{C}$ group bivalent (Figures 2 and 3). Bivalent 6 is on the average longer than bivalent 7 in mitotic $(6,7)$ as well as in meiotic nuclei (4). Therefore, it is concluded that the pachytene bivalent carrying the marker is number 6 . The mean relative length and centromere index of this bivalent are $5.6 \pm 0.4$ and $42 \pm 4$, respectively. The mean diameter of the marker is at early pachytene $0.42 \mu \mathrm{m}$ compared to a value of $0.53 \mu \mathrm{m}$ at mid-late pachytene. The ultrastructural characteristics of the marker remain unchanged throughout pachytene. The occurrence of the marker in nuclei from the different individuals is given in Tables I and II. The marker has been found in 93 percent of the early pachytene nuclei and in 75 percent of the mid-late pachytene nuclei. In cases number 2, 3 and 7 the marker is present in all nuclei while in cases $1,4,5$, and 6 some of the nuclei lack the marker. Marker number 6 thus varies both within an individual as well as between individuals.

The marker on bivalent 6 is useful in the identification of the pachytene bivalents of 
human spermatocytes as an unequivocal identification of this bivalent improves the distinction between the $\mathrm{C}$ group bivalents as well as between the longer bivalents as a whole.

\subsection{Marker D}

Marker $D$ is located near the middle of the long arm of one of the $\mathrm{D}$ group bivalents and can only be recognized in early pachytene nuclei (Figure 4). The mean diameter of the marker is $0.46 \mu \mathrm{m}$. Its occurrence in nuclei from the different individuals is given in Tables I and II. The results suggest that case 4 does not possess the marker while its occurrence in the remainder of the cases is suggestive of a variation within individuals as is the case for marker number 6 .

The bivalent carrying the marker is on the average the longest of the D group bivalents and the marker has never been found on the shortest D group bivalent.

It is thus likely that the marker is on either bivalent 13 or 14 .

\section{CONCLUSION}

The composition and function of these chromatin differentiations are at present unclear. Morphological counterparts to the markers have not been reported in light microscopical analyses of meiotic $(4,5)$ or mitotic chromosomes $(6,9)$.

\section{ACKNOWLEDGEMENTS}

The work was supported by grant 202-76-1 BIO DK from the Commission of the European Communities and by the Danish Medical Research Council.

\section{REFERENCES}

1. Berthelsen, J. G., M. FgGh \& N. E. SKakkeBAK: Electron microscopical analysis of meiotic chromosomes from human spermatocytes during and after treatment with steriod hormones. Carlsberg Res. Commun. 45, 9-23 (1980)

2. Holm, P. B. \& S. W. Rasmussen: Human meiosis I. The human pachytene karyotype analyzed by three dimensional reconstructions of the synaptonemal complex. Carlsberg Res. Commun. 42, 283-323 (1977)

3. Holm, P. B. \& S. W. Rasmussen: Human meiosis III. Electron microscopical analysis of chromosome pairing in an individual with a balanced translocation $46, X Y,((5 p-; 22 p+)$. Carlsberg Res. Commun. 43, 329-350 (1978)

4. Hultén. M.: Chiasma distribution in the normal human male. Hereditas 76, 55-78 (1974)

5. Hungerford, D. A.: Chromosome structure and function in man. I. Pachytene mapping in the maie, improved methods and a general discussion of initial results. Cytogenetics 10, 23-32 (1971)

6. LUNDSTEEN, C.: Aspects of automated chromosome analysis. Thesis. Lægeforeningens Forlag, Copenhagen (1979)

7. Paris Conference (1971): Standardization in human cytogenetics. Cytogenetics 11, 313-362 (1972)

8. Rasmussen. S. W. \& P. B. Holm: Human meiosis II. Chromosome pairing and recombination nodules in human spermatocytes. Carlsberg Res Commun. 43, 257-327 (1978)

9. Yunis, J. J.: High resolution of human chromosomes. Science 191, 1268-1270 (1976) 